\title{
REVIEW
}

\section{Chronic traumatic encephalopathy: a spectrum of neuropathological changes following repetitive brain trauma in athletes and military personnel}

Thor D Stein ${ }^{1,2,3,4,5}$, Victor E Alvarez ${ }^{2,4,6}$ and Ann C McKee ${ }^{1,3,4,5,6^{*}}$

\begin{abstract}
Chronic traumatic encephalopathy (CTE) is a progressive neurodegenerative disease that occurs in association with repetitive traumatic brain injury experienced in sport and military service. In most instances, the clinical symptoms of the disease begin after a long period of latency ranging from several years to several decades. The initial symptoms are typically insidious, consisting of irritability, impulsivity, aggression, depression, short-term memory loss and heightened suicidality. The symptoms progress slowly over decades to include cognitive deficits and dementia. The pathology of CTE is characterized by the accumulation of phosphorylated tau protein in neurons and astrocytes in a pattern that is unique from other tauopathies, including Alzheimer's disease. The hyperphosphorylated tau abnormalities begin focally, as perivascular neurofibrillary tangles and neurites at the depths of the cerebral sulci, and then spread to involve superficial layers of adjacent cortex before becoming a widespread degeneration affecting medial temporal lobe structures, diencephalon and brainstem. Most instances of CTE (>85\% of cases) show abnormal accumulations of phosphorylated $43 \mathrm{kDa}$ TAR DNA binding protein that are partially colocalized with phosphorylated tau protein. As CTE is characterized pathologically by frontal and temporal lobe atrophy, by abnormal deposits of phosphorylated tau and by $43 \mathrm{kDa}$ TAR DNA binding protein and is associated clinically with behavioral and personality changes, as well as cognitive impairments, CTE is increasingly categorized as an acquired frontotemporal lobar degeneration. Currently, some of the greatest challenges are that CTE cannot be diagnosed during life and the incidence and prevalence of the disorder remain uncertain. Furthermore, the contribution of age, gender, genetics, stress, alcohol and substance abuse to the development of CTE remains to be determined.
\end{abstract}

\section{Introduction}

The concept that chronic neurodegeneration might occur after minor brain trauma was first introduced in 1927 by Osnato and Gilberti, who studied 100 clinical cases of concussion of the brain, defined as a blow to the head with loss of consciousness with or without post-traumatic amnesia or skull fracture, and found several instances in which the clinical symptoms persisted and secondary degenerative changes developed, a condition they termed traumatic encephalitis [1]. Subsequently, in 1928 Harrison Martland, a New Jersey pathologist, outlined a symptom complex well recognized in professional pugilists

\footnotetext{
* Correspondence: amckee@bu.edu

${ }^{1} V A$ Boston HealthCare System, 150 South Huntington Avenue, Boston MA 02130, USA

${ }^{3}$ Department of Pathology and Laboratory Medicine, Boston University School of Medicine, 72 East Concord Street, Boston, MA 02118, USA Full list of author information is available at the end of the article
}

that appeared to result from repeated sublethal blows to the head [2]. In his monograph 'Punch Drunk', Martland described unsteadiness of gait, mental confusion, slowing of muscular movements, occasionally combined with hesitancy in speech, tremors of the hands and nodding of the head. This condition was later referred to as dementia pugilistica, traumatic progressive encephalopathy, and chronic traumatic encephalopathy (CTE) to highlight its chronic and progressive nature [3-7].

Isolated reports of the neuropathology of CTE appeared in the literature in the 1950s and 1960s [6-12], but it was not until 1973 with the detailed description of the clinical and neuropathological features of 15 retired boxers by Corsellis, Bruton and Freeman-Browne [13] that a relatively stereotyped pattern of structural brain abnormalities began to emerge. These changes included cerebral atrophy, enlargement of the lateral and third 
ventricles, thinning of the corpus callosum, cavum septum pellucidum with fenestrations and cerebellar scarring. Cresyl violet and Von Braunmühl's silver stains also demonstrated neuronal loss in the cerebellar tonsils and substantia nigra, neurofibrillary degeneration of the substantia nigra and cerebral cortex, and senile plaques in $27 \%$ of cases. In later reports using beta-amyloid $(A \beta)$ immunohistochemistry, it was determined that $95 \%$ of cases of CTE showed widespread diffuse $A \beta$ deposits $[14,15]$. Coincident with the rising interest in $A \beta$ pathology in Alzheimer's disease (AD), the demonstration of $A \beta$ deposits in $30 \%$ of cases of acute trauma and amyloid precursor protein abnormalities after axonal injury [16-21], there was a surge of interest in the role of $A \beta$ and amyloid precursor protein in CTE pathogenesis. However, as accumulating studies by multiple investigators using multiple techniques demonstrate no $A \beta$ pathology in most cases of CTE, particularly in young individuals [22-29] and in early stages [29], and instead indicate an association between $\mathrm{A} \beta$ deposition and the age of the subject at death [29], it is becoming increasingly less likely that $A \beta$ or amyloid precursor protein plays a major role in the initiation of CTE.

CTE is distinguished from other neurodegenerative disorders by a distinctive topographic and cellular pattern of tau neurofibrillary pathology. Using a combination of thioflavine $\mathrm{S}$ staining, silver methods and tau immunocytochemistry, Hof and colleagues noted the striking distribution of neurofibrillary tangles (NFTs) in layer II and the upper third of layer III of neocortical areas in CTE, which differs from the preferential distribution of NFTs in layers V to VI in AD [22]. Hof and colleagues also observed that NFTs in two other environmentally triggered tauopathies - post-encephalitic Parkinson disease and Guamanian amyotrophic lateral sclerosis (ALS) parkinsonism/dementia - are particularly distributed to layers II and III of the neocortex, suggesting specific involvement of short-distance, forwardprojecting corticocortical neurons in these disorders. Compared with $\mathrm{AD}$, the size of individual NFTs in CTE is generally larger [22] and the neurites are less threadlike, and more dot-like and spindle shaped $[15,29]$. The conspicuous tendency of the phosphorylated tau (p-tau) neurofibrillary pathology in CTE to be perivascular and irregularly concentrated at the sulcal depths was first noted by Geddes and colleagues [23,24], who described the neuropathological alterations of five young men ranging in age from 23 to 28 years. Two men were young boxers, one was a soccer player, one was mentally subnormal with a long history of head banging, and another was an epileptic patient who frequently hit his head during seizures. They noted argyrophilic, tau-positive neocortical NFTs, strikingly arranged in groups around small intracortical blood vessels, usually associated with neuropil threads and granular tau positive neurons in the absence of $A \beta$.

The early, focal perivascular changes of CTE [23,24,27-29] differ substantially from p-tau pathology of the Alzheimer type reported in some cognitively normal young adults [30], in opiate abusers [31], and in nondemented older subjects such as those in the Framingham Heart Study [32] or the Honolulu Asian Aging Study $[33,34]$. Furthermore, unlike emerging or preclinical AD pathology, medial temporal lobe p-tau pathology is not an early or preclinical manifestation of CTE, although it is a feature of well-established disease.

The tau isoform profile and phosphorylation state in CTE are similar to those in AD [35] and the neuronal tau pathology shows immunoreactivity to both threerepeat tau and four-repeat tau [29]. Furthermore, in the areas affected early in CTE (that is, sulcal depths, perivascular and subpial regions), the four-repeat isoform of tau is predominantly expressed (data not published and [29]). While astrocytic p-tau pathology in CTE is predominantly four-repeat tau immunopositive and may be substantial in some instances, it is topographically distinct from the four-repeat tau immunoreactive thornshaped astrocytes that have been reported in the medial temporal lobe in aging and $\mathrm{AD}$ [36,37]. Furthermore, unlike thorn-shaped astrocytes, p-tau-positive astrocytes in CTE may form astrocytic tangles. Individual CTE cases vary in the relative degree of neuronal or astrocytic tau pathology; some cases display prominent tauimmunoreactive astrocytes while other cases show predominantly NFTs. Whether the relative involvement of neurons compared with astrocytes reflects any underlying pathogenetic differences remains to be determined. In the early stages of CTE there is consistent involvement of the locus coeruleus with neurofibrillary p-tau pathology. Phosphorylated tau deposition in the locus coeruleus has been reported in young control brains [30]; however, not all neuropathological studies of young control subjects support this observation [29,31]. A possible explanation for the discrepancy may be that not all studies screen young control subjects for exposure to mild traumatic brain injury (mTBI); in the Braak report, for example, no clinical history of head trauma was made available despite the fact that $17 \%$ of the subjects died from acute trauma or accidental death and that mTBI is common among young subjects [30].

\section{Staging system}

Based on our recent analysis of postmortem brains from 68 subjects with CTE (all men ranging in age from 17 to 98 years (mean 59.5 years), including 64 athletes, 21 military veterans ( $86 \%$ of whom were also athletes) and one individual who engaged in self-injurious headbanging behavior), CTE can be classified into four 
pathological stages based on a stereotyped pattern of structural change and tau pathology [29]. Incremental increases in other pathologies, such as $43 \mathrm{kDa}$ TAR DNA binding protein (TDP-43) immunoreactivity and axonopathy, are also characteristic of the four stages. The CTE stage correlates with the progression of clinical symptoms, and among American football players the stage of CTE at death significantly correlates with age at death, number of years playing football, and number of years after retirement from football [29]. However, it remains unclear whether all cases progress, and progress at similar rates, or whether some instances of CTE persist indefinitely as early-stage disease. The stages of CTE pathology are as follows.

\section{Stage I}

Most brains with stage I CTE $(n=7)$ are grossly unremarkable, although mild enlargement of the frontal horns of the lateral ventricles is found occasionally. Microscopically, there are isolated perivascular foci of $\mathrm{p}-$ tau NFTs, neuropil threads and astrocytic tangles. These clusters of tau pathology are most common at the depths of cerebral sulci of the superior, dorsolateral, lateral, and inferior frontal cortices (Figures 1 and 2). ptau-positive astrocytes are usually found in the subpial region directly overlying the perivascular foci. The only other region that shows p-tau neurofibrillary degeneration in two-thirds of cases of stage I CTE is the locus coeruleus. Scant NFTs may be found in other structures, such as the amygdala, entorhinal cortex, hippocampus, medulla, and cingulate gyrus. About one-half of stage I cases will also have abnormal TDP-43 inclusions within the subcortical frontal white matter and fornix [29]. A $\beta$ plaques or vascular amyloid deposits are not found. There is often a brisk gliosis of the white matter, most pronounced at the apex of the gyri and at the junction between the deep layers of cortex and underlying white matter. Neighboring small vessels, arterioles as well as venules, may show accumulation of hemosiderin-laden macrophages and the meninges may be mildly gliotic.

\section{Stage II}

Macroscopic abnormalities are found in approximately one-half of cases with stage II CTE $(n=14)$, including mild enlargement of the frontal horns of the lateral ventricles and third ventricle, a cavum septum, and pallor of the locus coeruleus and substantia nigra. Microscopically, multiple foci of tau pathology are found at the depths of the sulci commonly in the superior, dorsolateral, lateral, and inferior frontal, the anterior inferior and lateral temporal, inferior and superior parietal, insular and septal cortices (Figure 3). These foci typically consist of collections of p-tau NFTs and neurites surrounding small vessels and focal subpial p-tau astrocytic
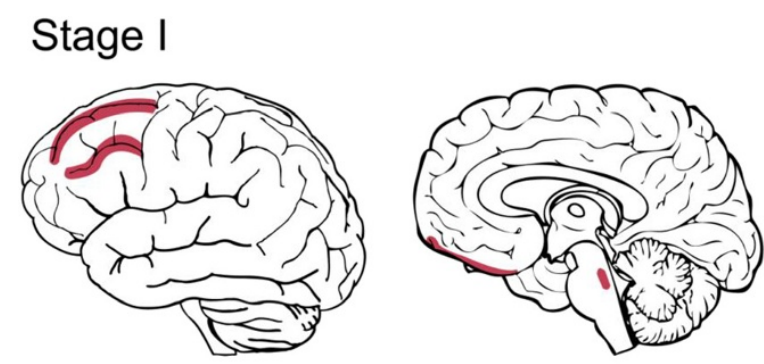

\section{Stage II}
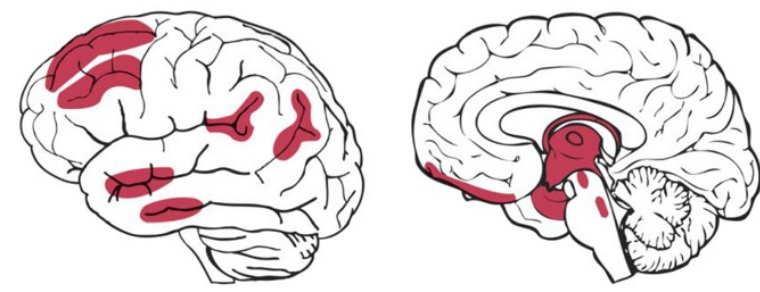

\section{Stage III}
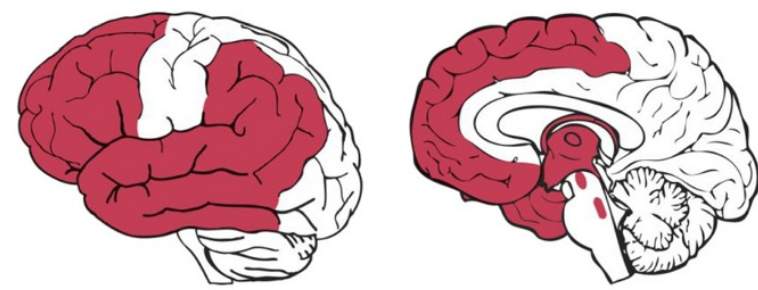

\section{Stage IV}
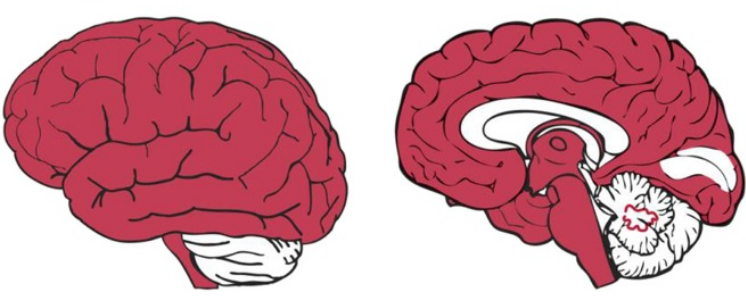

Figure 1 Four stages of chronic traumatic encephalopathy. Schematic of the regions involved by tau pathology in the four neuropathological stages of chronic traumatic encephalopathy.

pathology. In contrast to stage I, NFTs are also found in superficial layers of the adjacent cerebral cortex extending into the gyral crest. NFTs are present within the locus coeruleus and substantia innominata. Most cases show no substantial NFT pathology in the medial temporal lobe structures. Deep structures such as the substantia nigra, dorsal and median raphe and thalamus show mild neurofibrillary degeneration. TDP-43 pathology occurs in most subjects and consists of rare neuropil threads and inclusions within the cerebral subcortical white matter, medial temporal lobe, and brainstem, most often in a distribution that mirrors the tau pathology. $A \beta$ pathology is not found in stage II CTE. 


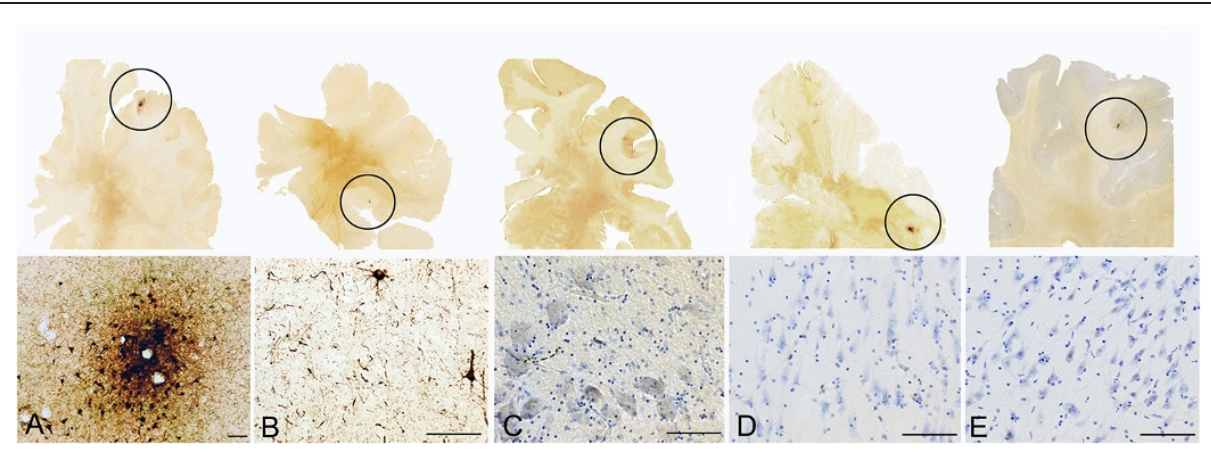

Figure 2 Stage I chronic traumatic encephalopathy. In stage I chronic traumatic encephalopathy, phosphorylated tau ( $p$-tau) pathology is found in limited discrete perivascular foci (A), typically at the depths of sulci or around small vessels (black circles). There is limited p-tau pathology in the cortex adjacent to the involved foci (B). Occasional p-tau neurites are found in the nucleus basalis of Meynert (C). There is no pathology in the amygdala (D) or CA1 of the hippocampus (E). CP-13-immunostained $50 \mu \mathrm{m}$ tissue sections, some counterstained with cresyl violet. Scale bar $=100 \mu \mathrm{m}$. Adapted from [29].

\section{Stage III}

Grossly, most cases of stage III CTE $(n=15)$ show a reduction in brain weight, mild atrophy of the frontal and temporal lobes and enlargement of the lateral and third ventricles. Septal abnormalities are common (50\%), including cavum septum or septal fenestrations. There is usually pallor of the locus coeruleus and substantia nigra, atrophy of the mammillary bodies, thalamus and hypothalamus, and thinning of the corpus callosum. Microscopically, NFTs are present diffusely in the frontal, temporal and parietal cortices and are most concentrated around small vessels and at the depths of sulci. Cortices involved include superior, dorsolateral, and inferior frontal, septal, insular, temporal pole, superior, middle, and inferior temporal, and inferior parietal. The hippocampus, entorhinal cortex, amygdala, nucleus basalis of Meynert, and locus coeruleus show extensive neurofibrillary pathology (Figure 4). Frequent NFTs are also present in hypothalamus, mammillary bodies, substantia nigra and dorsal and median raphe nuclei. There are sparse NFTs in the Rolandic and cingulate cortices, thalamus, nucleus accumbens, and dorsal motor nucleus of the vagus. In about one-third of cases, mild neurofibrillary pathology is also found in the dentate nucleus of the cerebellum and spinal cord (Figure 1). The majority of cases show TDP-43-positive neurites and inclusions in the cerebral cortex, medial temporal lobe, diencephalon and brainstem. Although most cases of stage III
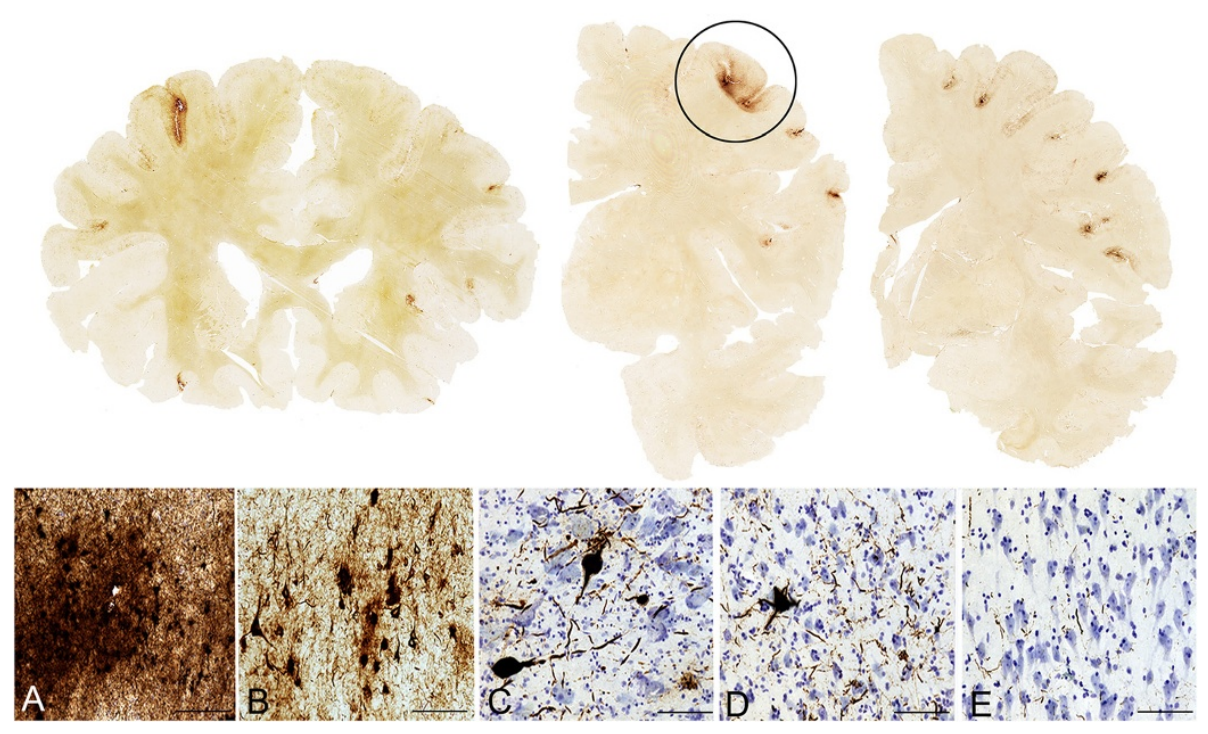

Figure 3 Stage II chronic traumatic encephalopathy. In stage II chronic traumatic encephalopathy, there is spread of pathology from focal epicenters (A) to the superficial layers of adjacent cortex (B). The nucleus basalis of Meynert (C) shows moderate neurofibrillary tangles and neurites. The medial temporal lobe shows only mild neurofibrillary pathology, including the amygdala (D) and CA1 of the hippocampus (E). CP13-immunostained $50 \mu \mathrm{m}$ tissue sections, some counterstained with cresyl violet. Scale bar $=100 \mu \mathrm{m}$. Adapted from [29]. 

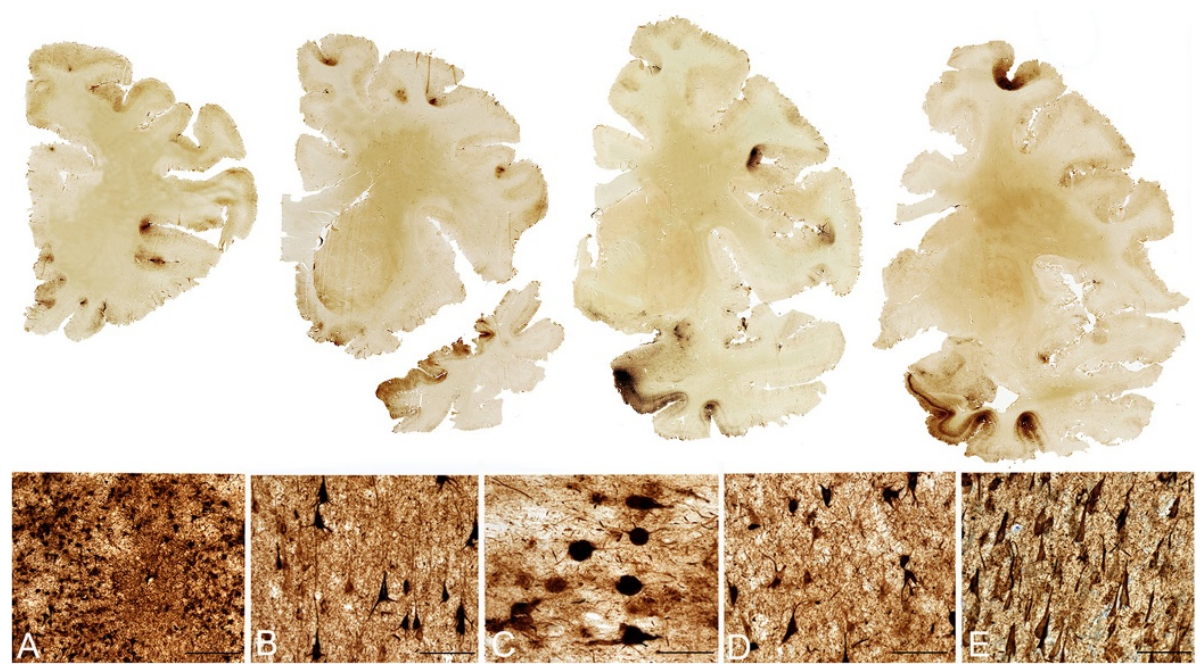

Figure 4 Stage III chronic traumatic encephalopathy. In stage III chronic traumatic encephalopathy, phosphorylated tau pathology is severe and widespread throughout the frontal, insular, temporal, and parietal cortices. The cortical epicenters and depths of the sulci often consist of confluent masses of neurofibrillary tangles (NFTs) and astrocytic tangles (A). The intervening cortices show advanced neurofibrillary degeneration (B). The nucleus basalis of Meynert shows dense NFTs (C). The amygdala (D) and hippocampus (E) show marked neurofibrillary pathology. CP-13immunostained $50 \mu \mathrm{m}$ tissue sections, some counterstained with cresyl violet. Scale bar $=100 \mu \mathrm{m}$. Adapted from [29].

CTE show no $A \beta$ deposition, sparse diffuse and neuritic $\mathrm{A} \beta$ plaques are found in approximately $13 \%$.

Stage IV Brain weight in stage IV CTE $(n=15)$ is significantly decreased; there may be marked global atrophy of the brain (Figure 5). There is usually pronounced atrophy of the frontal and temporal lobes, medial temporal lobe and anterior thalamus. The hypothalamic floor is thinned, the mammillary bodies are darkly discolored and atrophied, and there is marked enlargement of the lateral and third ventricles. Approximately two-thirds of subjects will have septal abnormalities including cavum septum, fenestrations, or absence. There is generalized atrophy of the white matter, often with yellow-tan discoloration; the posterior body of the corpus callosum just anterior to the splenium is often disproportionately

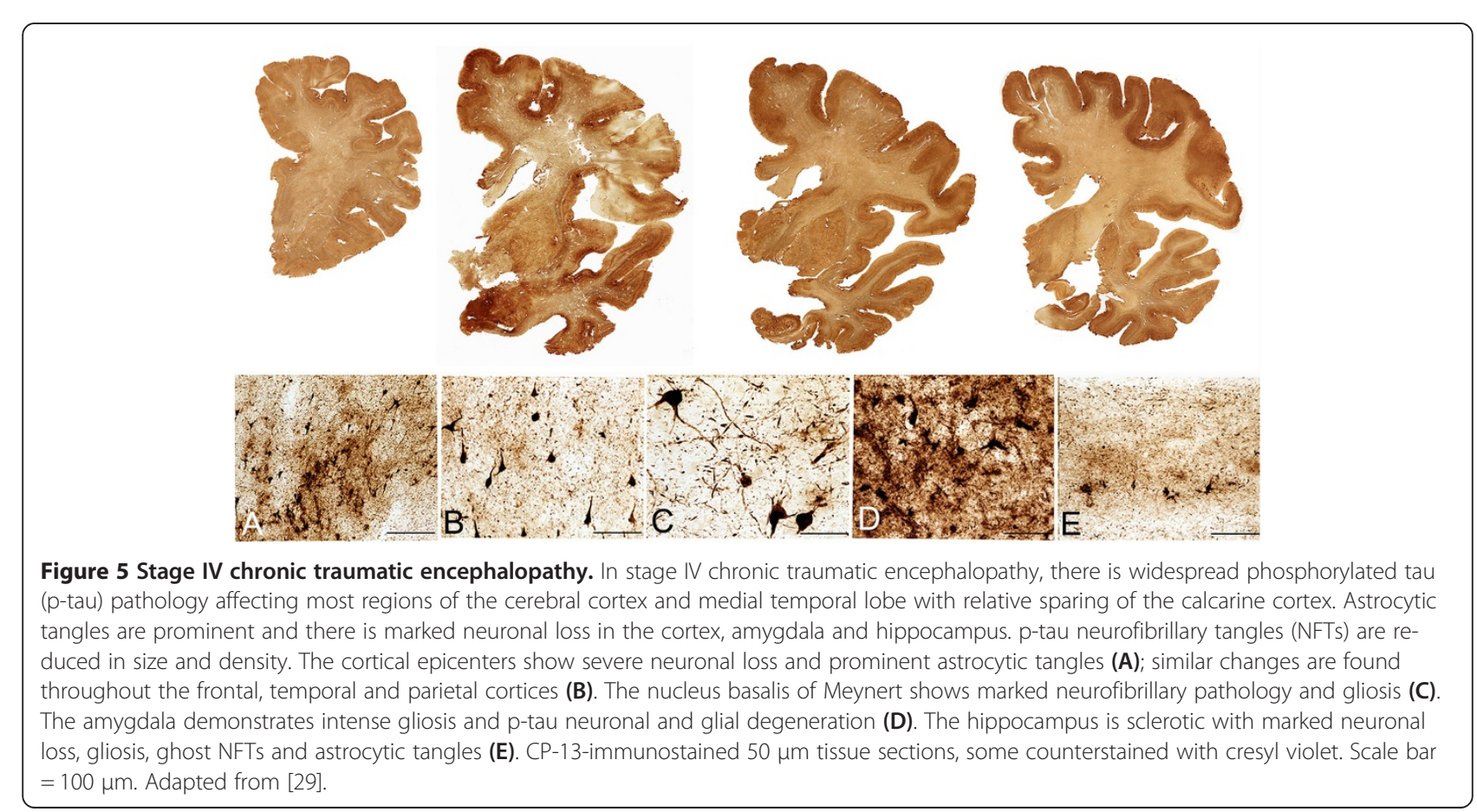




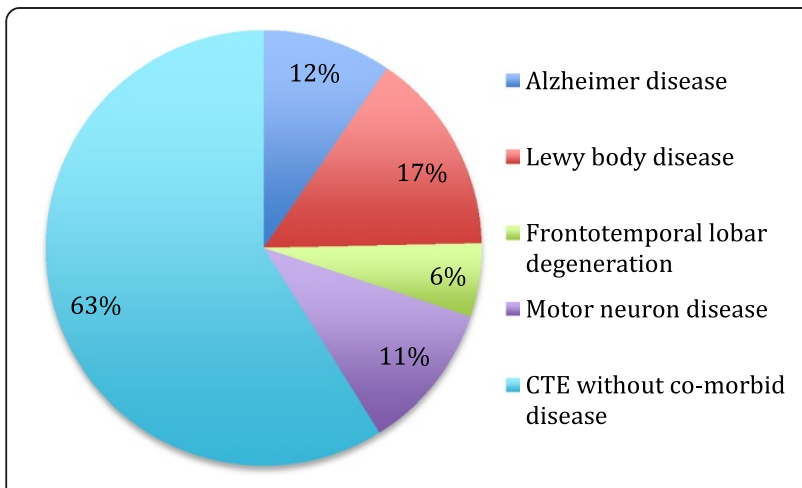

Figure 6 Chronic traumatic encephalopathy with comorbid disease. Percentage of cases with chronic traumatic encephalopathy (CTE) with and without comorbidity. Of those cases with CTE and Alzheimer's disease, 43\% had overlapping Lewy body disease; of those with CTE and frontotemporal lobar degeneration, $50 \%$ also had Lewy body disease.

thin. The locus coeruleus and substantia nigra are very pale.

Microscopically, there is severe spongiosus of layer 2 of the cerebral cortex and widespread neuronal loss. Neurons in the substantia nigra are severely depleted. There is prominent, patchy, widespread myelin loss and astrocytosis of the white matter of the cerebral hemispheres with perivascular macrophage deposition. There is also severe tau deposition, as clusters of glial tangles and small NFTs in a patchy irregular distribution throughout frontal, temporal and parietal cortices. Neurofibrillary degeneration is extremely severe in the insula, septal, temporal cortex, amygdala, hippocampus, entorhinal cortex, substantia nigra and locus coeruleus. The calcarine cortex is relatively spared although $39 \%$ of cases show some p-tau pathology. In stage IV CTE, NFTs are found widely distributed throughout the hippocampal formation including the dentate gyrus, CA3, CA2 and CA4. CA1 is typically severely sclerotic, with few remaining neurons and only p-tau immunoreactive astrocytes. In stage IV CTE, p-tau pathology also generally involves the cerebellum, including the dentate nucleus, granular cell and layers, and the medial lemniscus and inferior olives of the medulla. There is marked loss and distortion of axons throughout the cerebral and cerebellar white matter. TDP-43 deposition is severe and widespread with dense accumulations of dot-like and thread-like inclusions in neurites and intra-neuronal cytoplasmic inclusions in all cases.

\section{$43 \mathrm{kDa}$ TAR DNA binding protein pathology}

Abnormal TDP-43 inclusions are a consistent feature of CTE and occur in over one-half of stage I cases and in all of stage IV cases. In early stages the inclusions consist of neuritic threads and dot-like inclusions typically found in subpial, perivascular and periventricular regions; cytoplasmic neuronal inclusions are first seen in stage II disease and are characteristic of late stages. The TDP-43 inclusions in CTE partially colocalize with p-tau inclusions in neurons [38]. TDP-43 is an RNA-binding protein that regulates RNA metabolism, including mRNA splicing, stability and transport [39,40]. After acute traumatic injury in animal models, TDP-43 expression is upregulated and TDP-43 relocates from the neuronal nucleus to accumulate in the neuronal cytoplasm $[41,42]$. TDP-43 binds to many cellular transcripts including tau and alpha-synuclein and its dysregulation may underlie some of the pathologies seen with these proteins [43]. In particular, TDP-43 may influence tau isoform expression [44]. There is also evidence that alteration in tau protein metabolism including hyperphosphorylation, tau phosphatase resistance, and deposition of p-tau intracellular aggregates may be found in diseases characterized by abnormal TDP-43 metabolism, such as ALS [45].

\section{Axonal damage in chronic traumatic encephalopathy}

In addition to p-tau pathology, axonal pathology is present at all stages of CTE and appears to progress with stage of CTE $[28,29]$. In the earliest stages of disease, phosphorylated neurofilament immunohistochemistry shows distorted axonal varicosities in the cortex, subcortical white matter, and deep white matter tracts of the diencephalon. By stage III, severe axonal loss and pathological profiles are found in the subcortical white matter, and are most severe in the frontal and temporal lobes. In advanced CTE, there is widespread axonal loss with frequent severely distorted axonal profiles widely distributed in the subcortical white matter. Remaining axons are swollen and dystrophic and some contain p-tau or TDP-43 [27]. The temporal and spatial progression of the changes suggests that axonal injury is fundamental to the initiation and propagation of the tau and TDP-43 proteinopathies.

\section{Chronic traumatic encephalopathy with comorbid degenerative disease}

CTE is associated with the development of other neurodegenerations, notably Lewy body disease (LBD), AD, frontotemporal lobar degeneration (FTLD) and motor neuron disease (MND) [29,46]. Among 71 combined cases of pathologically confirmed CTE, coexistent LBD was found in $17 \%$ of cases, MND in $11 \%, \mathrm{AD}$ in $12 \%$, and FTLD in 6\% (Figure 6). In comparison, in our experience with Boston University's Alzheimer's Disease Center (BUADC) of 313 subjects with AD, 27\% had comorbid LBD, 2.6\% had FTLD, and none had MND. Furthermore, the average age at death of subjects with CTE is younger than those with $\mathrm{AD}$ in the BUADC brain bank, suggesting that these comorbidities are not simply 
age related. Indeed, the frequent presence of comorbid pathologies in CTE suggests that either repetitive trauma or the accumulation of tau pathology in CTE provokes the deposition of other abnormal proteins involved in neurodegeneration $[29,46]$.

\section{Alzheimer disease}

Epidemiologic evidence suggests that trauma is a risk factor for dementia, most often of the Alzheimer type [47-50]. In our cohort of subjects with CTE, $44 \%$ have some deposition of amyloid (diffuse, neuritic, or vascular), 35\% have neuritic plaques, and $12 \%$ meet the criteria for $\mathrm{AD}$ (Figure 6) [29]; other reports indicate severe vascular $A \beta$ deposition in advanced CTE [51]. Whether trauma-associated $\mathrm{AD}$ is pathologically distinct from $\mathrm{AD}$ unassociated with head injury is not yet known, but detailed study of those individuals with both CTE and AD may help uncover any such differences as well as the neurodegenerative mechanism underlying post-traumatic degeneration. There also may be differences in neurodegeneration following single moderate to severe traumatic brain injury (TBI) compared with repetitive mTBI. An autopsy study of single TBI survivors found $A \beta$ plaques and p-tau NFTs in one-third of subjects, suggesting that $\mathrm{AD}$ may contribute to neurodegeneration after TBI [52]. A postmortem study of a collegeeducated woman involved in a serious motor vehicle accident at age 39, who developed progressive dementia and parkinsonism 11 years later, showed evidence of multiple neurodegenerations including atypical AD, severe LBD (with exceptionally large Lewy bodies), axonopathy and TDP-43 proteinopathy [53].

\section{Lewy body disease}

A large proportion of CTE cases have a concomitant diagnosis of LBD (17\%) and even more show at least isolated Lewy bodies in the brainstem or amygdala (23\%) $[29,46]$. Alpha-synuclein has been shown to accumulate in axons following severe TBI [54]. Some evidence suggests alpha-synuclein and tau may synergistically influence the aggregation of one another [55-58] and this may form a molecular basis by which LBD develops in cases of CTE. Indeed, of those cases with LBD, 27\% (3/11) also had AD and 18\% (2/11) had FTLD, suggesting that the presence of one disease may increase the risk for another. Although most individuals with advanced CTE have neuronal loss and tau pathology in the substantia nigra, the frequent presence of alpha-synuclein and development of LBD may partially explain the high frequency of Parkinsonism that occurs in individuals with CTE.

\section{Frontotemporal lobar degeneration}

Six percent of CTE cases also had concurrent FTLD, although the total number is small $(n=4)$ [2]. One-half of these cases were FTLD with tau-positive inclusions, including one case of Pick's disease and one of progressive supranuclear palsy, and one-half were FTLD with TDP43-positive inclusions, which might reflect the dual tau and TDP-43 proteinopathies found in CTE. Because CTE is accompanied by a range of symptoms reflective of frontotemporal dysfunction, including behavioral and cognitive deficits and a dysexecutive syndrome, and the anatomic substrate of CTE is a FTLD characterized by superficial spongiosus, atrophy and neuronal loss with astrocytic and neuronal deposition of tau and TDP-43, CTE is increasingly categorized as an acquired FTLD.

\section{Chronic traumatic encephalopathy with motor neuron disease}

Some data suggest that trauma and athletic exposure are risk factors for developing ALS [59-62], although there are conflicting reports regarding a single head injury [63] and whether more than one head injury is necessary [64]. Recent data in American football players who played professionally for more than five seasons show that the risk of dying from ALS is more than four times greater than age-matched and gender-matched controls. In our series of 68 subjects, approximately $11 \%$ of individuals with CTE developed a progressive MND [29,38]. Most (63\%) presented with motor weakness, atrophy and fasciculations indistinguishable from sporadic ALS and developed mild cognitive and behavioral symptoms several years after the onset of motor signs [29]. Individuals who present with motor symptoms of MND have milder CTE at death (stages II and III), a reflection of their shortened lifespan, whereas those who present with cognitive symptoms die with advanced CTE (stages III and IV). In all cases, there is a distinct TDP-43 proteinopathy affecting the brain and spinal cord [29,38]. In several ways, CTE is similar to Guamanian ALS parkinsonism/dementia, another environmentally triggered tauopathy associated with MND, further suggesting that alterations in tau and TDP43 metabolism might be mechanistically linked [45].

\section{Trauma exposure}

Many sports have now been associated with CTE, including boxing, American football, ice hockey, soccer, rugby and wrestling. In addition, CTE has been identified in military veterans, individuals who participate in self-injurious head-banging behavior, victims of physical abuse or assaults, poorly controlled epileptics, and a dwarf who worked for 15 years as a circus clown, participated in dwarf-throwing events and had been knocked unconscious 'a dozen times' [27,29].

CTE can only be diagnosed with certainty at autopsy and ascertainment bias is high in an autopsy series; therefore, the incidence and prevalence of the disorder are not known. Of former professional football players 
who have died and donated their brains to research, the percentage of players who have pathologically confirmed CTE has been variously reported as 50\% [46], 87\% [65] or 97\% [29], often in combination with comorbid neurodegenerative disease. While many players had a history of repeated concussions, some did not - suggesting that exposure to football even in the absence of symptomatic or reported concussions is associated with CTE. Although all known cases of CTE have had a history of repetitive $\mathrm{mTBI}$, a lingering question concerns the role of other environmental factors, such as performanceenhancing drugs, alcohol, opiates or physiological stress in accelerating or enhancing the development of tauopathy and subsequent neurodegeneration. Multiple rodent studies have shown that glucocorticoids and stress increase tau phosphorylation and cognitive deficits [66-69] and p-tau immunoreactivity in opiate user brains is significantly higher than age-matched controls [31].

\section{Military veterans}

TBI is considered the signature wound among service members in the Iraq and Afghanistan wars, especially mTBI related to exposure to an explosive blast [70-72]. Although the neurobiological effects of blast-induced neurotrauma are more complex than mTBI from other causes [73], the mechanisms involved put these individuals at risk for developing CTE [27]. Military personnel are also at risk for concussive mTBI during training exercises, recreational activities, combat or participation in sports. CTE has been documented in 22 military veterans, most of whom were also athletes $[27,29,74]$. Ten veterans saw combat: five in the Iraq and Afghanistan conflicts, one in the Gulf War, two in Vietnam, and two in World War II. Three veterans with CTE experienced a moderate to severe TBI while in service; five veterans were exposed to blast from improvised explosive devices and explosive munitions. Four veterans of the Iraq and Afghanistan conflicts with CTE were also diagnosed with post-traumatic stress disorder $[27,74]$.

\section{Pathogenetic mechanisms}

How repetitive mTBI triggers a chronic progressive neurodegeneration is not known but key mechanisms probably include axonal injury, tau hyperphosphorylation, misfolding and aggregation, cytoskeletal breakdown and disrupted axonal transport. During acute TBI, the brain undergoes shear deformation that elongates and injures axons, small blood vessels, and astrocytes [75-78]. Axons are particularly vulnerable given their length and high axolemma:cytoplasm ratio. Traumatic axonal injury produces changes in axolemma permeability, ionic shifts including massive influx of calcium, and release of caspases and calpains that trigger the misfolding, truncation, phosphorylation and aggregation of many proteins, including tau and TDP-43 and the breakdown of the microtubules and neurofilaments that disrupts axonal transport. Repetitive injury and accumulation of misfolded p-tau aggregates might eventually overwhelm normal clearance mechanisms, allowing $\mathrm{p}$-tau to spread transynaptically and interneuronally, possibly involving protein templating mechanisms and extracellular cerebrospinal fluid clearance pathways [79-82]. In addition, the initial trauma also damages small vessels and the blood-brain barrier, producing inflammation and microhemorrhage. P-tau aggregates might also provoke the deposition of other abnormal protein aggregates, including $A \beta$, alpha-synuclein and TDP-43, all of which compound the neurodegeneration.

\section{Animal models}

Several animal models of mTBI have recently been developed that offer the opportunity to examine the relationship between repetitive trauma and CTE, as well as to study the contribution of genetics, inflammatory response, age, gender, and substance use to the neurodegeneration. In the Goldstein model of blast neurotrauma, wild-type mice exposed to a single controlled sublethal blast developed p-tau immunoreactivity, axonopathy, microvascular pathology, and widespread astrocytosis and microgliosis similar to early CTE changes found after blast-related or sportsrelated concussion [28]. These mice also showed slowed axonal conduction and impaired spatial learning and memory that persisted for 1 month after blast exposure. Further investigation is warranted to determine whether the changes are progressive and whether repeated exposures to blast accelerate the neuropathology and functional deficits.

Mouzon and colleagues studied the effects of repetitive and single closed impact injury in wild-type mice [83]. Transient deficits in motor function and spatial memory, reactive astrocytosis and axonal injury were produced by single mTBI, whereas mice exposed to five mTBIs administered at 48-hour intervals over 8 days developed significantly greater cognitive impairment, microglial activation, reactive astrocytosis, and multifocal axonal pathology [83].

A similar study using 18-month-old human tau transgenic mice that express wild-type human tau isoforms on a null murine tau background found significant increases in p-tau immunoreactivity, reactive astrocytosis and microgliosis in mice exposed to repetitive mTBI, but not in mice exposed to single mTBI [84].

\section{Conclusions}

Mild, repetitive traumatic injury produces multifocal axonal injury that triggers the accumulation of p-tau as CTE. Although the process begins focally, it gradually spreads to involve widespread regions of the brain 
including the frontal and temporal lobes, medial temporal lobe, diencephalon, and brainstem. TDP-43 abnormalities are found in most CTE cases; in advanced CTE, TDP-43 pathology is severe and widespread. As tau and TDP-43 deposition increases, there is a parallel increase in axonal pathology and loss. CTE is associated with the development of other neurodegenerative diseases, including AD, LBD, FTLD and MND. At the present time, CTE can only be diagnosed at autopsy, but promising efforts to develop p-tau PET ligands and cerebrospinal fluid biomarkers are underway to diagnose and monitor the course of disease in living subjects. The contribution of age, gender, genetics, drugs and physiological stress to the development of CTE remains to be determined. Future therapeutic efforts in CTE will need to address the effects of acute mTBI, the initial deposition of abnormal p-tau deposits, the progressive spread of p-tau throughout the nervous system, and the neuronal loss and neurodegeneration that follows. Currently, the best therapies are prevention of the initial trauma and continued public education regarding proper detection and management of minor traumatic head injuries.

Note: This article is part of a series on Traumatic brain injury, edited by Robert Stern. Other articles in this series can be found at http://alzres.com/series/traumaticbraininjury

\section{Abbreviations}

AD: Alzheimer's disease; ALS: Amyotrophic lateral sclerosis; AB: Beta amyloid; BUADC: Boston University's alzheimer's disease center; CTE: Chronic traumatic encephalopathy; FTLD: Frontotemporal lobar degeneration; LBD: Lewy body disease; MND: Motor neuron disease; mTBI: mild traumatic brain injury; NFT: Neurofibrillary tangle; p-tau: phosphorylated tau; TBI: Traumatic brain injury; TDP-43: 43 kDa TAR DNA binding protein.

\section{Competing interests}

The authors declare that they have no competing interests.

\section{Acknowledgements}

The authors gratefully acknowledge the use of resources and facilities at the Edith Nourse Rogers Memorial Veterans Hospital (Bedford, MA, USA), the help of all members of the Center for the Study of Traumatic

Encephalopathy at Boston University and the Boston VA, as well as the individuals and families whose participation and contributions made this work possible. This work was supported by the Department of Veterans Affairs, the Veterans Affairs Biorepository (CSP 501), the Translational Research Center for Traumatic Brain Injury and Stress Disorders Veterans Affairs Rehabilitation Research and Development Traumatic Brain Injury Center of Excellence (B6796-C), the National Institute of Aging Boston University Alzheimer's Disease Center (P30AG13846; supplement 0572063345-5), the National Institute of Aging Boston University Framingham Heart Study R01 (AG1649), the Sports Legacy Institute, and the National Operating Committee on Standards for Athletic Equipment. This work was also supported by unrestricted gifts from the National Football League, the Andlinger Foundation and Worldwide Wrestling Entertainment.

\section{Author details}

'VA Boston HealthCare System, 150 South Huntington Avenue, Boston, MA 02130, USA. ${ }^{2}$ Bedford VA Medical Center, 200 Springs Road, Bedford, MA 01730, USA. ${ }^{3}$ Department of Pathology and Laboratory Medicine, Boston
University School of Medicine, 72 East Concord Street, Boston, MA 02118 USA. ${ }^{4}$ Department of Neurology, Boston University School of Medicine, 72 East Concord Street, Boston, MA 02118, USA. ${ }^{5}$ Alzheimer Disease Center, Boston University School of Medicine, 72 East Concord Street, Boston, MA 02118, USA. ${ }^{6}$ Center for the Study of Traumatic Encephalopathy, Boston University School of Medicine, 72 East Concord Street, Boston, MA 02118, USA.

\section{Published: 15 Jan 2014}

\section{References}

1. Osnato M: Postconcussion neurosis-traumatic encephalitis - a conception of postconcussion phenomena. Arch NeurPsych 1927, 18:181-214.

2. Martland H: Punch drunk. JAMA 1928, 91:1103-1107.

3. Millsbaugh JA: Dementia pugilistica. US Naval Med Bulletin 1937, 35:297-361.

4. Critchley M: Punch-Drunk Syndromes: the Chronic Traumatic Encephalopathy of Boxers. Hommage a Clovis Vincent. Paris: Maloin; 1949.

5. McCown IA: Protecting the boxer. JAMA 1959, 169:1409-1413.

6. Brandenburg W, Hallervorden J: Dementia pugilistica with anatomical findings. Virchows Arch 1954, 325:680-709.

7. Grahmann H, Ule G: [Diagnosis of chronic cerebral symptoms in boxers (dementia pugilistica \& traumatic encephalopathy of boxers)]. Psychiatr Neurol 1957, 134:261-283.

8. Neubuerger KT, Sinton DW, Denst J: Cerebral atrophy associated with boxing. AMA Arch Neurol Psychiatry 1959, 81:403-408.

9. Courville CB: Punch drunk. Its pathogenesis and pathology on the basis of a verified case. Bull L A Neurol Soc 1962, 27:160-168.

10. Mawdsley C, Ferguson FR: Neurological disease in boxers. Lancet 1963, 2:799-801.

11. Constantinidis J, Tissot R: [Generalized Alzheimer's neurofibrillary lesions without senile plaques. (Presentation of one anatomo-clinical case)]. Schweiz Arch Neurol Neurochir Psychiatr 1967, 100:117-130.

12. Payne EE: Brains of boxers. Neurochirurgia 1968, 11:173-188.

13. Corsellis JA, Bruton CJ, Freeman-Browne D: The aftermath of boxing. Psychol Med 1973, 3:270-303.

14. Roberts GW, Allsop D, Bruton C: The occult aftermath of boxing. I Neurol Neurosurg Psychiatry 1990, 53:373-378.

15. Tokuda T, Ikeda S, Yanagisawa N, Ihara Y, Glenner GG: Re-examination of ex-boxers' brains using immunohistochemistry with antibodies to amyloid beta-protein and tau protein. Acta Neuropathol 1991, 82:280-285

16. Ikonomovic MD, Uryu K, Abrahamson EE, Ciallella JR, Trojanowski JQ, Lee VM, Clark RS, Marion DW, Wisniewski SR, DeKosky ST: Alzheimer's pathology in human temporal cortex surgically excised after severe brain injury. Exp Neurol 2004, 190:192-203.

17. Roberts GW, Gentleman SM, Lynch A, Murray L, Landon M, Graham DI: Beta amyloid protein deposition in the brain after severe head injury: implications for the pathogenesis of Alzheimer's disease. J Neurol Neurosurg Psychiatry 1994, 57:419-425.

18. Roberts GW, Gentleman SM, Lynch A, Graham DI: Beta A4 amyloid protein deposition in brain after head trauma. Lancet 1991, 338:1422-1423.

19. Gentleman SM, Greenberg BD, Savage MJ, Noori M, Newman SJ, Roberts GW, Griffin WS, Graham DI: A beta 42 is the predominant form of amyloid beta-protein in the brains of short-term survivors of head injury. Neuroreport 1997, 8:1519-1522.

20. Olsson A, Csajbok L, Ost M, Höglund K, Nylén K, Rosengren L, Nellgård B, Blennow K: Marked increase of beta-amyloid (1-42) and amyloid precursor protein in ventricular cerebrospinal fluid after severe traumatic brain injury. J Neurol 2004, 251:870-876.

21. Smith DH, Chen XH, Iwata A, Graham DI: Amyloid beta accumulation in axons after traumatic brain injury in humans. J Neurosurg 2003, 98:1072-1077

22. Hof PR, Bouras C, Buée L, Delacourte A, Perl DP, Morrison JH: Differential distribution of neurofibrillary tangles in the cerebral cortex of dementia pugilistica and Alzheimer's disease cases. Acta Neuropathol 1992, 85:23-30.

23. Geddes JF, Vowles GH, Robinson SF, Sutcliffe JC: Neurofibrillary tangles, but not Alzheimer-type pathology, in a young boxer. Neuropathol Appl Neurobiol 1996, 22:12-16. 
24. Geddes JF, Vowles GH, Nicoll JA, Révész T: Neuronal cytoskeletal changes are an early consequence of repetitive head injury. Acta Neuropathol 1999, 98:171-178.

25. Omalu BI, DeKosky ST, Hamilton RL, Minster RL, Kamboh MI, Shakir AM, Wecht $\mathrm{CH}$ : Chronic traumatic encephalopathy in a national football league player: part II. Neurosurg 2006, 59:1086-1093.

26. Omalu BI, Fitzsimmons RP, Hammers J, Bailes J: Chronic traumatic encephalopathy in a professional American wrestler. J Forensic Nurs 2010, 6:130-136.

27. McKee AC, Cantu RC, Nowinski CJ, Hedley-Whyte ET, Gavett BE, Budson AE, Santini VE, Lee HS, Kubilus CA, Stern RA: Chronic traumatic encephalopathy in athletes: progressive tauopathy after repetitive head injury. J Neuropathol Exp Neurol 2009, 68:709-735.

28. Goldstein LE, Fisher AM, Tagge CA, Zhang X-L, Velisek L, Sullivan JA, Upreti C, Kracht JM, Ericsson M, Wojnarowicz MW, Goletiani CJ, Maglakelidze GM, Casey N, Moncaster JA, Minaeva O, Moir RD, Nowinski CJ, Stern RA, Cantu RC, Geiling J, Blusztajn JK, Wolozin BL, Ikezu T, Stein TD, Budson AE, Kowall NW, Chargin D, Sharon A, Saman S, Hall GF, et al: Chronic traumatic encephalopathy in blast-exposed military veterans and a blast neurotrauma mouse model. Sci Transl Med 2012, 4:134ra60.

29. McKee AC, Stein TD, Nowinski CJ, Stern RA, Daneshvar DH, Alvarez VE, Lee H-S, Hall G, Wojtowicz SM, Baugh CM, Riley DO, Kubilus CA, Cormier KA, Jacobs MA, Martin BR, Abraham CR, IkezU T, Reichard RR, Wolozin BL Budson AE, Goldstein LE, Kowall NW, Cantu RC: The spectrum of disease in chronic traumatic encephalopathy. Brain 2013, 136:43-64.

30. Braak H, Del Tredici K: The pathological process underlying Alzheimer's disease in individuals under thirty. Acta Neuropathol 2011, 121:171-181.

31. Anthony IC, Norrby KE, Dingwall T, Carnie FW, Millar T, Arango JC, Robertson R, Bell JE: Predisposition to accelerated Alzheimer-related changes in the brains of human immunodeficiency virus negative opiate abusers. Brain 2010, 133:3685-3698.

32. Au R, Seshadri S, Knox K, Beiser A, Himali JJ, Cabral HJ, Auerbach S, Green RC, Wolf PA, McKee AC: The Framingham Brain Donation Program: neuropathology along the cognitive continuum. Curr Alzheimer Res 2012 9:673-686.

33. White $L$ : Brain lesions at autopsy in older Japanese-American men as related to cognitive impairment and dementia in the final years of life: a summary report from the Honolulu-Asia aging study. J Alzheimer Dis 2009, 18:713-725.

34. Gelber RP, Launer LJ, White LR: The Honolulu-Asia Aging Study: epidemiologic and neuropathologic research on cognitive impairment. Curr Alzheimer Res 2012, 9:664-672.

35. Schmidt ML, Zhukareva V, Newell KL, Lee VM, Trojanowski JQ: Tau isoform profile and phosphorylation state in dementia pugilistica recapitulate Alzheimer's disease. Acta Neuropathol 2001, 101:518-524.

36. López-González I, Carmona M, Blanco R, Luna-Muñoz J, Martínez-Mandonado A, Mena R, Ferrer I: Characterization of thorn-shaped astrocytes in white matter of temporal lobe in Alzheimer's disease brains. Brain Pathol 2013, 23:144-153.

37. Lace G, Ince PG, Brayne C, Savva GM, Matthews FE, de Silva R, Simpson JE, Wharton SB: Mesial temporal astrocyte tau pathology in the MRC-CFAS ageing brain cohort. Dement Geriatr Cogn Disord 2012, 34:15-24.

38. McKee AC, Gavett BE, Stern RA, Nowinski CJ, Cantu RC, Kowall NW, Perl DP, Hedley-Whyte ET, Price B, Sullivan C, Morin P, Lee HS, Kubilus CA, Daneshvar DH, Wulff M, Budson AE: TDP-43 proteinopathy and motor neuron disease in chronic traumatic encephalopathy. J Neuropathol Exp Neurol 2010, 69:918-929.

39. Sephton CF, Cenik B, Cenik BK, Herz J, Yu G: TDP-43 in central nervous system development and function: clues to TDP-43-associated neurodegeneration. Biol Chem 2012, 393:589-594.

40. Sephton CF, Cenik C, Kucukural A, Dammer EB, Cenik B, Han Y, Dewey CM Roth FP, Herz J, Peng J, Moore MJ, Yu G: Identification of neuronal RNA targets of TDP-43-containing ribonucleoprotein complexes. J Biol Chem 2011, 286:1204-1215.

41. Moisse K, Mepham J, Volkening K, Welch I, Hill T, Strong MJ: Cytosolic TDP43 expression following axotomy is associated with caspase 3 activation in NFL-/- mice: support for a role for TDP-43 in the physiological response to neuronal injury. Brain Res 2009, 1296:176-186.

42. Moisse K, Volkening K, Leystra-Lantz C, Welch I, Hill T, Strong MJ: Divergent patterns of cytosolic TDP-43 and neuronal progranulin expression following axotomy: implications for TDP-43 in the physiological response to neuronal injury. Brain Res 2009, 1249:202-211.
43. Sato T, Takeuchi S, Saito A, Ding W, Bamba H, Matsuura H, Hisa Y, Tooyama I, Urushitani M: Axonal ligation induces transient redistribution of TDP-43 in brainstem motor neurons. Neuroscience 2009, 164:1565-1578.

44. Morales R, Green KM, Soto C: Cross currents in protein misfolding disorders: interactions and therapy. CNS Neurol Disord Drug Targets 2009, 8:363-371.

45. Strong MJ, Yang W: The frontotemporal syndromes of ALS. Clinicopathological correlates. J Mol Neurosci 2011, 45:648-655.

46. Hazrati LN, Tartaglia MC, Diamandis P, Davis KD, Green RE, Wennberg R, Wong JC, Ezerins L, Tator CH: Absence of chronic traumatic encephalopathy in retired football players with multiple concussions and neurological symptomatology. Front Hum Neurosci 2013, 7:222.

47. Heyman A, Wilkinson WE, Stafford JA, Helms MJ, Sigmon AH, Weinberg T: Alzheimer's disease: a study of epidemiological aspects. Ann Neurol 1984, 15:335-341.

48. Mayeux R, Ottman R, Tang MX, Noboa-Bauza L, Marder K, Gurland B, Stern $Y$ : Genetic susceptibility and head injury as risk factors for Alzheimer's disease among community-dwelling elderly persons and their firstdegree relatives. Ann Neurol 1993, 33:494-501.

49. Plassman BL, Havlik RJ, Steffens DC, Helms MJ, Newman TN, Drosdick D, Phillips C, Gau BA, Welsh-Bohmer KA, Burke JR, Guralnik JM, Breitner JC: Documented head injury in early adulthood and risk of Alzheimer's disease and other dementias. Neurol 2000, 55:1158-1166.

50. Lehman EJ, Hein MJ, Baron SL, Gersic CM: Neurodegenerative causes of death among retired National Football League players. Neurol 2012, 79:1970-1974

51. Jordan BD, Kanik BA, Horwich MS, Sweeney D, Relkin NR, Petito CK, Gandy S: Apolipoprotein E epsilon 4 and fatal cerebral amyloid angiopathy associated with dementia pugilistica. Ann Neurol 1995, 38:698-699.

52. Johnson VE, Stewart $W$, Smith DH: Widespread $\tau$ and amyloid- $\beta$ pathology many years after a single traumatic brain injury in humans. Brain Pathol 2012, 22:142-149.

53. Daneshvar DH, Katz DI, Stein TD, Alvarez VE, McKee AC: Atypical Alzheimer's disease, Lewy body disease, and TDP-43 proteinopathy following single traumatic brain injury [abstract]. Alzheimers Dement 2013, 9:P438.

54. Uryu K, Chen XH, Martinez D, Browne KD, Johnson VE, Graham DI, Lee VM, Trojanowski JQ, Smith DH: Multiple proteins implicated in neurodegenerative diseases accumulate in axons after brain trauma in humans. Exp Neurol 2007, 208:185-192.

55. Geddes JW: Alpha-synuclein: a potent inducer of tau pathology. Exp Neurol 2005, 192:244-250.

56. Frasier M, Walzer M, McCarthy L, Magnuson D, Lee JM, Haas C, Kahle P, Wolozin B: Tau phosphorylation increases in symptomatic mice overexpressing A30P alpha-synuclein. Exp Neurol 2005, 192:274-287.

57. Badiola N, de Oliveira RM, Herrera F, Guardia-Laguarta C, Gonçalves SA, Pera M, Suárez-Calvet M, Clarimon J, Outerio TF, Lleó A: Tau enhances asynuclein aggregation and toxicity in cellular models of synucleinopathy. Plos One 2011, 6:e26609.

58. Jellinger KA: Interaction between pathogenic proteins in neurodegenerative disorders. J Cell Mol Med 2012, 16:1166-1183.

59. Chío A, Calvo A, Dossena M, Ghiglione P, Mutani R, Mora G: ALS in Italian professional soccer players: the risk is still present and could be soccer-specific. Amyotroph Lateral Scler 2009, 10:205-209.

60. Wicks P, Ganesalingham J, Collin C, Prevett M, Leigh NP, Al-Chalabi A: Three soccer playing friends with simultaneous amyotrophic lateral sclerosis. Amyotroph Lateral Scler 2007, 8:177-179.

61. Chiò A: Severely increased risk of amyotrophic lateral sclerosis among Italian professional football players. Brain 2005, 128:472-476.

62. Schmidt S, Kwee LC, Allen KD, Oddone EZ: Association of ALS with head injury, cigarette smoking and APOE genotypes. J Neurol Sci 2010, 291:22-29.

63. Armon C, Nelson LM: Is head trauma a risk factor for amyotrophic lateral sclerosis? An evidence based review. Amyotroph Lateral Scler 2012, 13:351-356.

64. Chen H, Richard M, Sandler DP, Umbach DM, Kamel F: Head injury and amyotrophic lateral sclerosis. Am J Epidemiol 2007, 166:810-816.

65. Omalu B, Bailes J, Hamilton RL, Kamboh MI, Hammers J, Case M, Fitzsimmons R: Emerging histomorphologic phenotypes of chronic traumatic encephalopathy in American athletes. Neurosurgery 2011, 69:173-183. 
66. Okawa Y, Ishiguro K, Fujita SC: Stress-induced hyperphosphorylation of tau in the mouse brain. FEBS Lett 2003, 535:183-189.

67. Green KN, Billings LM, Roozendaal B, McGaugh JL, LaFerla FM: Glucocorticoids increase amyloid-beta and tau pathology in a mouse model of Alzheimer's disease. J Neurosci 2006, 26:9047-9056.

68. Sotiropoulos I, Catania C, Riedemann T, Fry JP, Breen KC, Michaelidis TM, Almeida OF: Glucocorticoids trigger Alzheimer disease-like pathobiochemistry in rat neuronal cells expressing human tau. J Neurochem 2008, 107:385-397.

69. Sotiropoulos I, Catania C, Pinto LG, Silva R, Pollerberg GE, Takashima A, Sousa N, Almeida OF: Stress acts cumulatively to precipitate Alzheimer's disease-like tau pathology and cognitive deficits. J Neurosci 2011, 31:7840-7847.

70. Hoge CW, McGurk D, Thomas JL, Cox AL, Engel CC, Castro CA: Mild traumatic brain injury in U.S. Soldiers returning from Iraq. N Engl J Med 2008, 358:453-463.

71. Terrio H, Brenner LA, Ivins BJ, Cho JM, Helmick K, Schwab K, Scally K, Bretthauer R, Warden D: Traumatic brain injury screening: preliminary findings in a US Army Brigade Combat Team. J Head Trauma Rehabil 2009, 24:14-23.

72. Owens BD, Kragh JF, Wenke JC, Macaitis J, Wade CE, Holcomb JB: Combat wounds in operation Iraqi Freedom and operation Enduring Freedom. J Trauma 2008, 64:295-299.

73. Cernak I, Merkle AC, Koliatsos VE, Bilik JM, Luong QT, Mahota TM, Xu L, Slack $N$, Windle D, Ahmed FA: The pathobiology of blast injuries and blast-induced neurotrauma as identified using a new experimental model of injury in mice. Neurobiol Dis 2011, 41:538-551.

74. Omalu B, Hammers JL, Bailes J, Hamilton RL, Kamboh MI, Webster G, Fitzsimmons RP: Chronic traumatic encephalopathy in an Iraqi war veteran with posttraumatic stress disorder who committed suicide. Neurosurg Focus 2011, 31:E3.

75. Tang-Schomer MD, Patel AR, Baas PW, Smith DH: Mechanical breaking of microtubules in axons during dynamic stretch injury underlies delayed elasticity, microtubule disassembly, and axon degeneration. FASEB J 2010, 24:1401-1410

76. Chen LJ, Wang YJ, Tseng GF: Compression alters kinase and phosphatase activity and tau and MAP2 phosphorylation transiently while inducing the fast adaptive dendritic remodeling of underlying cortical neurons. J Neurotrauma 2010, 27:1657-1669.

77. Johnson VE, Stewart W, Smith DH: Axonal pathology in traumatic brain injury. Exp Neurol 2012, 246:35-43.

78. Serbest G, Burkhardt MF, Siman R, Raghupathi R, Saatman KE: Temporal profiles of cytoskeletal protein loss following traumatic axonal injury in mice. Neurochem Res 2007, 32:2006-2014.

79. Frost B, Jacks RL, Diamond MI: Propagation of tau misfolding from the outside to the inside of a cell. J Biol Chem 2009, 284:12845-12852.

80. de Calignon A, Polydoro M, Suárez-Calvet M, William C, Adamowicz DH, Kopeikina KJ, Pitstick R, Sahara N, Ashe KH, Carlson GA, Spires-Jones TL, Hyman BT: Propagation of tau pathology in a model of early Alzheimer's disease. Neuron 2012, 73:685-697.

81. Hall G, Patuto B: Is tau ready for admission to the prion club? Prion 2012 6:223-233.

82. Iliff JJ, Wang M, Liao Y, Plogg BA, Peng W, Gundersen GA, Benveniste $H$ Vates GE, Deane R, Goldman SA, Nagelhus EA, Nedergaard M: A paravascular pathway facilitates CSF flow through the brain parenchyma and the clearance of interstitial solutes, including amyloid $\beta$. Sci Trans/ Med 2012, 4:147ra111.
83. Mouzon B, Chaytow H, Crynen G, Bachmeier C, Stewart J, Mullan M, Stewart W, Crawford F: Repetitive mild traumatic brain injury in a mouse model produces learning and memory deficits accompanied by histological changes. J Neurotrauma 2012, 29:2761-2773.

84. Ojo JO, Mouzon B, Greenberg MB, Bachmeier C, Mullan M, Crawford F: Repetitive mild traumatic brain injury augments tau pathology and glial activation in aged hTau mice. J Neuropathol Exp Neurol 2013, 72:137-151.

\subsection{6/alzrt234}

Cite this article as: Stein et al:: Chronic traumatic encephalopathy: a spectrum of neuropathological changes following repetitive brain trauma in athletes and military personnel. Alzheimer's Research \& Therapy 2014, 6:4 